J.Pharm.Dyn., 4, 552-558 (1981)

\title{
EFFECTS OF COLESTIPOL HYDROCHLORIDE ON CHOLESTEROL AND BILE ACIDS ABSORPTION IN THE RAT INTESTINAL TRACT
}

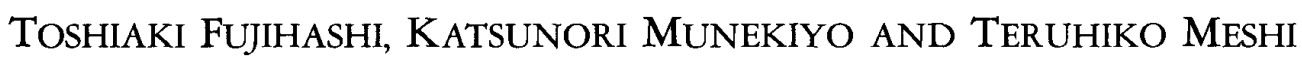

Pharmacology Function, Japan Upjohn Research Laboratories, 168 Ohyagi, Takasaki, Gunma 370, Japan

(Received December 18, 1980)

It was clearly shown that colestipol hydrochloride inhibits lymphatic absorption of not only endogenous but also exogenous cholesterol and triglyceride in thoracic duct cannulated rats. Inhibition of cholesterol absorption by colestipol hydrochloride was effectively blocked by administration of cholic acid. It was also suggested that colestipol hydrochloride inactivates bile acids which are essential for cholesterol absorption in the intestinal tract. Administration of colestipol hydrochloride to fasted rats decreased bile flow and biliary secretion of cholesterol and bile acids and increased fecal excretion of bile acids bound to colestipol hydrochloride. These results show that colestipol hydrochloride binds bile acids in the intestinal tract and interferes with bile acids reabsorption.

Keywords - colestipol hydrochloride; cholesterol; bile acids; intestinal tract; absorption; thoracic duct cannulation; binding

\section{INTRODUCTION}

Colestipol hydrochloride $\left(\mathrm{C}_{\mathrm{p}}\right)$ is an anionexchange resin polymerized with diethylenetriamine and 1-chloro-2,3-epoxypropane. It is not absorbed from the gastrointestinal tract. ${ }^{11} \mathrm{Cp}$ is known to effectively lower serum cholesterol in dogs, cockerels and humans. ${ }^{2-4)}$ No toxic effects have been detected in experimental and clinical usage. ${ }^{\text {) }}$

One in vitrostudy indicated that $\mathrm{Cp}$ binds with cholic acid, a major bile acid in human bile.2) It has been reported that fecal excretion of bile acids and sterols, ${ }^{3,6}$ hepatic syntheses of cholesterol and bile acids (unpublished data), and the metabolic turnover rate of cholesterol ${ }^{\text {) }}$ are increased after Cp administration for long periods. Parkinson et $a l^{2,4)}$ concluded that increased fecal loss of bile acids due to $\mathrm{Cp}$ administration leads to increased conversion of cholesterol to bile acids and decreased serum cholesterol levels.

Whether $\mathrm{Cp}$ binds with cholic acid in vivo has not been clearly established. The mechanism of $\mathrm{C}_{\mathrm{p}}$ action in the intestinal tract also remains unclear. Interference with dietary cholesterol absorption may be a factor in the reduction of serum cholesterol levels; in fact, $\mathrm{Cp}$ is known to counteract increases in serum cholesterol due to cholesterol and cholic acid feeding. ${ }^{6)}$ In the present study, the effect of $\mathrm{Cp}$ on the absorption of cholesterol and the interaction of $\mathrm{Cp}_{\mathrm{p}}$ with bile acids in the intestinal tract were investigated in rats.

\section{MATERIALS AND METHODS}

Male Sprague-Dawley rats (CD-CRJ) weighing approximately $300 \mathrm{~g}$ were used.

Effects of $C p$ on Cholesterol Absorption from the Intestinal Tract - In order to determine the direct effect of $\mathrm{Cp}$ on the intestinal absorption of cholesterol, the thoracic duct was cannulated and thoracic lymph was assayed for cholesterol. Cannulation was carried out by the modified method of Bollman et al $l^{8)}$ Animals were subsequently restrained in Bollman cages and fasted until the end of the experiment with free access to $0.9 \%$ saline solution. About $20 \mathrm{~h}$ after the operation, lymph was collected from cannulated rats in which the lymph flow was consistently greater 
than $1 \mathrm{ml} / \mathrm{h}$.

Cp suspended in $5 \mathrm{ml}$ of $0.25 \%$ methylcellulose was orally administered in doses of 150 and $300 \mathrm{mg} / \mathrm{rat}$. Cholestyramine, a quaternary ammonium styrenedivinylbenzene copolymer, ${ }^{9)}$ was also administered in a dose of $150 \mathrm{mg} / \mathrm{rat}(340 \mathrm{mg}$ as Questran ${ }^{\circledR}$, Mead Johnson Laboratories). The control group received $0.25 \%$ methylcellulose.

After administration of $\mathrm{Cp}$, lymph was collected at intervals of $2 \mathrm{~h}$ for 10 -h period and thereafter for $14 \mathrm{~h}$. Collected lymph was frozen until cholesterol and triglyceride analyses. At the end of the experiment, rats were laparotomized for inspection of the intestinal tract and the cannulated area for abnormalities.

Effects of $C p$ on Cholesterol Absorption with Varying Amounts of Bile Acids - The effects of $\mathrm{Cp}$ on lymphatic absorption of cholesterol after test emulsion administration were determined at 4 stages where bile acids levels in the intestinal tract were artificially varied. No Bile Acid (Stage 1): the common bile duct was cannulated and all bile diverted; Normal Bile Acid (Stage 2): no treatment with intact bile circulation; Increasing Bile Acid (Stage 3): $80 \mathrm{mg}$ cholic acid was orally given simultaneously with a test emulsion; and Excess Bile Acid (Stage 4): $240 \mathrm{mg}$ cholic acid was orally given simultaneously with a test emulsion.

Effects of $C p$ on the Enterohepatic Circulation of Bile Acids - In order to study the interaction of $\mathrm{CP}$ with bile acids in vivo, $\mathrm{Cp}$ was orally administered in a dose of $1 \mathrm{~g} / \mathrm{kg} / \mathrm{d}$ for 2 days under fasting conditions or in powdered laboratory chow (Oriental Yeast Industrial Co.) containing 2.5\% of $\mathrm{Cp}$ for 7 days.

Feces were collected for the last 2 days of the Cp treatment period and frozen until cholesterol and bile acids analyses. After $C_{p}$ treatment, rats were anesthetised with urethane $(1 \mathrm{~g} / \mathrm{kg}$ i.p. $)$ and cannulated in the common bile duct for the collection of bile for $2 \mathrm{~h}$ in an air-conditioned room (temperature: $27-29^{\circ} \mathrm{C}$; relative humidity: $40-45 \%)$. At the end of the experiment, the blood and liver were removed for cholesterol and bile acids analyses.

Chemical Analyses - Total cholesterol was extracted with $n$-hexane after alcoholic $\mathrm{KOH}$ hydrolysis of body fluid and measured with $o$ phthalaldehyde (Cholesterol B-Test Wako). Serum cholesterol was assayed enzymatically (Cholesterol C-Test Wako). Triglyceride in lymph was assayed using acetylacetone (Triglyceride $\mathrm{B}$-Test). Total bile acids were determined enzymatically (Sterognost-3 $\alpha$ Daiichi); bile was assayed after appropriate dilution with pure water, and other tissues after extraction with boiling ethanol followed by washing with a mixture of ether and $n$-heptane $(1: 1)$. Feces and the liver were homogenized in $95 \%$ ethanol by using a Polytron homogenizer (Kinematica). A portion of the homogenate was assayed for cholesterol and bile acids. Fecal bile acids were extracted with boiling ethanol (free bile acids fraction) and later reextracted with $1 \mathrm{~N} \mathrm{HCl}$ (bound bile acids fraction). The bound bile acids fraction is actually considered to be that bound to $\mathrm{Cp}$, since cholic acid bound to $C p$ is easily released in $1 \mathrm{~N} \mathrm{HCl}$ and not in boiling ethanol.

Student's t-test was used to establish significant differences in mean values between the control and treated groups.

\section{RESULTS}

\section{Effects of $C p$ on Cholesterol Absorption from the Intestinal Tract}

Total cholesterol and triglyceride contents in lymph collected from 18 to $44 \mathrm{~h}$ after cannulation were measured (Fig. 1, control group). These levels actually indicate the lymphatic reabsorption rate of endogenous cholesterol and triglyceride and maintainance of constant values throughout the experimental period of $24 \mathrm{~h}$. Cp $(150 \mathrm{mg} / \mathrm{rat})$ significantly reduced the reabsorption of cholesterol from 2 to $10 \mathrm{~h}$ after administration, but this value returned to the control level within $24 \mathrm{~h}$ (Fig. 1). Cp had a similar effect on the reabsorption of endogenous triglyceride.

Rats were orally given $3 \mathrm{ml}$ of a test emulsion containing $50 \mathrm{mg}$ cholesterol, $300 \mathrm{mg}$ triolein and $50 \mathrm{mg}$ bovine serum albumin in $0.25 \%$ methylcellulose to determine the effect of $\mathrm{Cp}$ on exogenous cholesterol absorption. Absorption of both 
cholesterol and triglyceride peaked 2 to $4 \mathrm{~h}$ after test emulsion administration and returned to normal values within $24 \mathrm{~h}$ (Fig. 2, control group). When administered simultaneously with the test emulsion, Cp (150 mg/rat) significantly inhibited the absorption of exogenous cholesterol. Cholestyramine $(150 \mathrm{mg} / \mathrm{rat})$ was somewhat more potent than an equal dose of Cp. At $300 \mathrm{mg} / \mathrm{rat}$ $\mathrm{Cp}_{\mathrm{p}}$ the inhibition was the greatest (Fig. 2).

Effects of Cp on Cholesterol Absorption with Varying Amounts of Bile Acids

This series of experiments was carried out to determine how $\mathrm{Cp}$ exerts inhibitory action on cholesterol absorption. Cholesterol absorption for $24 \mathrm{~h}$ after test emulsion administration increased as the bile acids level in the intestinal tract was artificially increased, as shown in Fig. 3. Cholesterol absorption was the highest at stages 3 and 4. Two doses of $C_{P}$ inhibited cholesterol absorption at stages 2 and 3. The amounts of cholesterol absorption inhibited by $\mathrm{Cp}$ were the same although the amounts of cholesterol

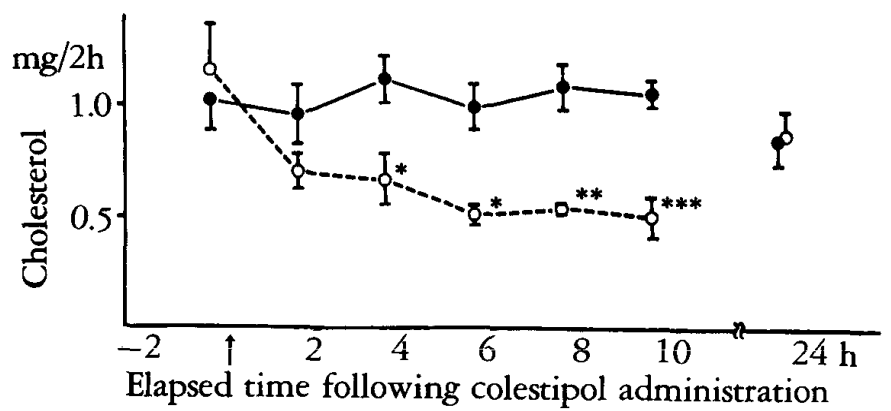

FIG. 1. Effects of Colestipol Hydrochloride on Lymphatic Reabsorption of Endogenous Cholesterol

Rats were orally administered with $C p(150$ $\mathrm{mg} / \mathrm{rat}$ ) about $20 \mathrm{~h}$ after thoracic duct cannulation (indicated by the arrow). Lymph was collected every $2 \mathrm{~h}$ for $10 \mathrm{~h}$ and thereafter for $14 \mathrm{~h}$. Each point represents the mean $\pm S . E$. of cholesterol in lymph collected for $2 \mathrm{~h} .-0$ : control group $(n=7)$, $\bigcirc-.-0$ : colestipol treated group $(n=4)$. ${ }^{*} p<0.05,{ }^{* *} p<0.01$, significantly different from the control group. absorbed varied significantly. Cp failed to inhibit cholesterol absorption at the excess bile acids level of stage 4.

Effects of Cp on the Enterohepatic Circulation of Bile Acids

Administration of Cp to fasted rats $(1 \mathrm{~g} / \mathrm{kg}$, for 2 days) reduced bile flow. This was accompanied by a reduction in bile acids contents in the liver and bile (Table I). $\mathrm{CP}_{\mathrm{P}}$ also reduced biliary cholesterol secretion. In order to determine whether this reduction was attributable to the inhibition of cholesterol absorption, 10 rats were cannulated in the thoracic duct (Lymph fistula group), 6 rats in the common bile duct (Bile fistula group), and 6 rats received an abdominal wall incision with no cannulation (sham opera-

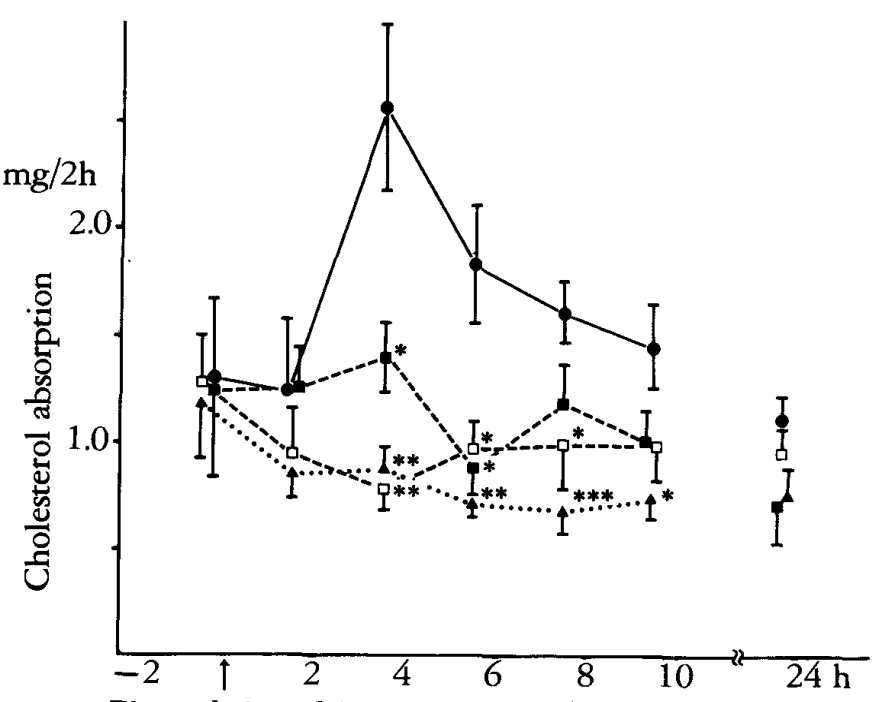

Elapsed time following test emulsion administration

FIG. 2. Effects of Colestipol Hydrochloride on Lymphatic Absorption of Cholesterol after Test Emulsion Administration

Thoracic duct cannulated rats were orally administered with a test emulsion containing $50 \mathrm{mg}$ cholesterol, $300 \mathrm{mg}$ triolein and $50 \mathrm{mg}$ serum albumin with $C p$ at the time indicated by the arrow. - - : control group (the test emulsion alone, $n=7), \mathbf{D}$ : colestipol treated group (150 $m g /$ rat, $n=6), \mathbf{\Lambda} \ldots . \mathbf{\Delta}$ : colestipol treated group $(300 \mathrm{mg} / \mathrm{rat}, \quad n=6) .{ }^{*} p<0.05,{ }^{* *} p<0.01$, ${ }_{* * *} p<0.001$, significantly different from the control group. 


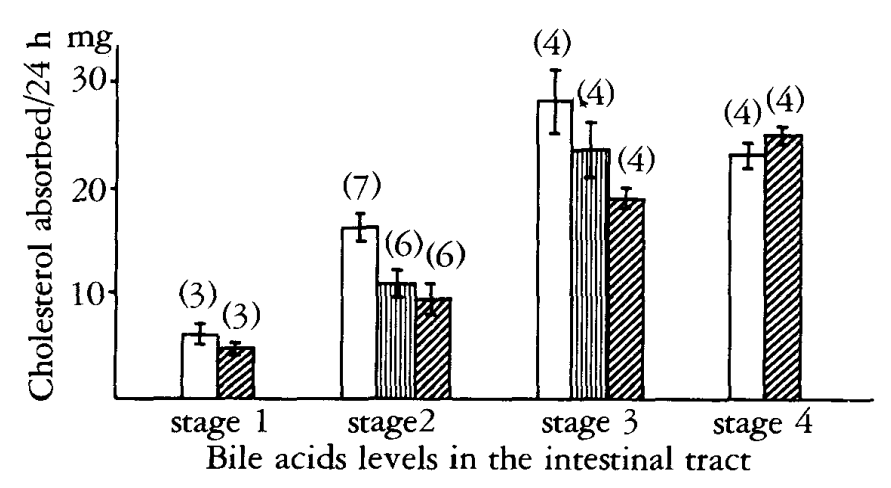

FIG. 3. Effects of Colestipol Hydrochloride on Lymphatic Absorption of Cholesterol with Varying Amounts of Bile Acids

Rats were administered a test emulsion with or without $C p 20 \mathrm{~h}$ after thoracic duct cannulation. Lymph was collected for the succeeding $24 \mathrm{~h}$ period. Bile acids contents in the intestinal tract were artificially manipulated as described in "Method.". Each column represents the mean \pm S.E. The values in parentheses are the number of rats used in each experiment. White column: control group; striped column: colestipol treated group (150 mg/rat); hatched column: colestipol treated group (300 $\mathrm{mg} / \mathrm{rat}$ ). tion goup). Treatment with lymph fistula produced no changes in bile flow and bile acids secretion while bile fistula produced a reduction in bile flow and bile acids secretion. Fecal excretion of bile acids, especially those of the bound bile acids fraction, was significantly increased by $\mathrm{Cp}$ treatment.

Table II shows that daily treatment of $\mathrm{Cp}$ for 7 days resulted in increased fecal bile acids and decreased biliary bile acids contents. Increased fecal cholesterol was also noted. Food consumption during the $C_{p}$ treatment period did not change compared to the control group (the averages for 7 days, control group: $22 \pm 1 \mathrm{~g} / \mathrm{d} ; \mathrm{Cp}$ treated group: $23 \pm 1 \mathrm{~g} / \mathrm{d}$ ), although the quantity of excreted feces in the $C_{p}$ treated group increased significantly $(p<0.01)$ due to excreted Cp (control group: $4.9 \pm 0.2 \mathrm{~g} / \mathrm{d} ; \mathrm{Cp}_{\mathrm{p}}$ treated group: $5.9 \pm 0.2 \mathrm{~g} / \mathrm{d})$.

\section{DUSCUSSION}

Essentially all absorbed cholesterol is transferred to thoracic lymph, ${ }^{10)}$ which can be collected at any time interval. Bile acids secretion, which is

TABALE I. Effects of Colestipol Hydrochloride on Bile Acids Secretion under Fasting Conditions

\begin{tabular}{|c|c|c|c|c|c|c|c|}
\hline Treatment & & & $\begin{array}{l}\text { Methylcellulose } \\
\text { (control) }\end{array}$ & Colestipol & $\begin{array}{c}\text { Sham } \\
\text { operation }^{a}\end{array}$ & $\begin{array}{l}\text { Lymph } \\
\text { fistula } a \text { ) }\end{array}$ & $\begin{array}{c}\text { Bile } \\
\text { fistula }^{a} \text { ) }\end{array}$ \\
\hline \multicolumn{3}{|l|}{ No. of rats } & $n=10$ & $n=10$ & $n=6$ & $n=10$ & $n=6$ \\
\hline \multirow{2}{*}{ Serum } & Cholesterol & (mg/dl) & $27.8 \pm 2.6$ & $30.1 \pm 3.4$ & $55.7 \pm 0.6$ & $68.4 \pm 6.2$ & $56.5 \pm 3.5$ \\
\hline & Bile acids & (mg/dl) & $3.1 \pm 0.3$ & $2.3 \pm 0.4$ & $2.7 \pm 0.7$ & $1.8 \pm 0.3$ & ND \\
\hline \multirow{2}{*}{ Liver } & Cholesterol & $(\mathrm{mg} / \mathrm{g})$ & $5.94 \pm 0.18$ & $5.15 \pm 0.35$ & $4.51 \pm 0.30$ & $4.82 \pm 0.22$ & $3.71 \pm 0.20$ \\
\hline & Bile acids & $(\mathrm{mg} / \mathrm{g})$ & $0.40 \pm 0.03$ & $0.32 \pm 0.02^{*}$ & $0.34 \pm 0.03$ & $0.35 \pm 0.02$ & $0.25 \pm 0.03 \#$ \\
\hline \multicolumn{2}{|l|}{ Bile flow } & $(\mathrm{ml} / \mathrm{h})$ & $0.69 \pm 0.05$ & $0.44 \pm 0.03^{* * *}$ & $0.69 \pm 0.06$ & $0.80 \pm 0.05$ & $0.40 \pm 0.07 \#$ \\
\hline \multirow{2}{*}{ Bile } & Cholesterol & $(\mu \mathrm{g} / \mathrm{h})$ & $178 \pm 17$ & $86 \pm 12^{* *}$ & $169 \pm 15$ & $148 \pm 12$ & $52 \pm 31 \# \#$ \\
\hline & Bile acids & $(\mathrm{mg} / \mathrm{h})$ & $14.0 \pm 1.5$ & $5.4 \pm 0.7^{* * *}$ & $12.2 \pm 1.6$ & $12.9 \pm 1.3$ & $1.5 \pm 0.3 \# \#$ \\
\hline \multirow{3}{*}{ Fecal $^{b)}$} & Cholesterol & $(\mathrm{mg} / \mathrm{d})$ & $1.36 \pm 0.29$ & $1.76 \pm 0.36$ & $0.96 \pm 0.17$ & $0.74 \pm 0.11$ & ND \\
\hline & Total bile acids & $(\mathrm{mg} / \mathrm{d})$ & $7.94 \pm 1.82$ & $14.72 \pm 2.28^{*}$ & $7.00 \pm 0.88$ & $4.68 \pm 0.94$ & $\mathrm{ND}$ \\
\hline & Bound bile acids ${ }^{c)}$ & $(\mathrm{mg} / \mathrm{d})$ & $0.81 \pm 0.30$ & $4.57 \pm 0.78^{* * *}$ & $0.60 \pm 0.22$ & $0.20 \pm 0.13$ & $\mathrm{ND}$ \\
\hline
\end{tabular}

Rats were administered $C p(1 \mathrm{~g} / \mathrm{kg}$ p.o.) once a day for 2 days, and allowed only tap water. These values represent the mean $\pm S . E$. ND: not determined.

a) The surgical operation was carried out 2 days before the experiment; rats were allowed onlly tap water.

b) Average 2-day value.

c) These values are for bile acids bound in residue after boiling ethanol extraction.

Significantly different from the control group; ${ }^{*} p<0.05,{ }^{* *} p<0.01,{ }^{* * *} p<0.001$.

Significantly different from the sham operation group, $\# p<0.05$, \#\# $p<0.01$. 
TABLE II. Effect of Colestipol Hydrochloride on Bile Acids Secretion

\begin{tabular}{|c|c|c|c|c|c|c|}
\hline \multicolumn{3}{|c|}{ Treatment } & \multicolumn{2}{|c|}{ Control } & \multicolumn{2}{|c|}{ Colestipol } \\
\hline \multicolumn{2}{|c|}{ No. of rats } & & \multicolumn{2}{|c|}{$n=6$} & \multicolumn{2}{|c|}{$n=6$} \\
\hline \multirow{2}{*}{ Serum } & Cholesterol & $(\mathrm{mg} / \mathrm{dl})$ & $60.5 \pm 3.0$ & & $56.3 \pm 2.4$ & \\
\hline & Bile acids & $(\mathrm{mg} / \mathrm{dl})$ & $2.9 \pm 0.2$ & & $2.4 \pm 0.4$ & \\
\hline \multirow{2}{*}{ Liver } & Cholesterol & $(\mathrm{mg} / \mathrm{g})$ & $3.58 \pm 0.12$ & & $2.99 \pm 0.07^{* *}$ & \\
\hline & Bile acids & $(\mathrm{mg} / \mathrm{g})$ & $0.37 \pm 0.04$ & & $0.29 \pm 0.02$ & \\
\hline \multicolumn{2}{|c|}{ Bile flow } & $(\mathrm{ml} / \mathrm{h})$ & $0.69 \pm 0.07$ & $0.61 \pm 0.03^{c)}$ & $0.73 \pm 0.04$ & $0.62 \pm 0.06^{c}$ \\
\hline \multirow{3}{*}{ Bile } & Cholesterol & $(\mu \mathrm{g} / \mathrm{h})$ & $157 \pm 20$ & $140 \pm 10^{c j}$ & $209 \pm 15$ & $142 \pm 34^{c)}$ \\
\hline & Bile acids & $(\mathrm{mg} / \mathrm{h})$ & $13.9 \pm 0.7$ & $9.3 \pm 0.7^{c)}$ & $11.4 \pm 0.7^{*}$ & $4.4 \pm 0.6_{* *}^{c}$ \\
\hline & Cholesterol & $(\mathrm{mg} / \mathrm{d})$ & $9.43 \pm 0.60$ & & $11.23 \pm 0.66^{*}$ & \\
\hline \multirow[t]{2}{*}{ Fecal $^{a)}$} & Total bile acids & $(\mathrm{mg} / \mathrm{d})$ & $19.13 \pm 0.60$ & & $31.23 \pm 1.55^{* *}$ & \\
\hline & Bound bile acids $\left.{ }^{b}\right)$ & $(\mathrm{mg} / \mathrm{d})$ & $2.58 \pm 0.14^{b}$ & & $9.11 \pm 0.61^{* *}$ & \\
\hline
\end{tabular}

Rats were maintained on powdered laboratory chow containing $2.5 \%$ Cp for 7 days; bile was collected for $2 h$ on day 8. These values represent the mean \pm S.E.

a) Feces were collected on days 6 and 7 of the treatment period; the value shown is the 2-day average.

b) These values are for bile acids bound in residue after boiling ethanol extraction.

c) These values are for bile collected in the later period (from 6 to $8 \mathrm{~h}$ after cannulation).

Significantly different from the control group; ${ }^{*} p<0.05,{ }^{* *} p<0.01,{ }^{* * *} p<0.001$.

believed to be essential for cholesterol absorption, ${ }^{11)}$ was not changed as a result of thoracic duct cannulation (see Table I). Thoracic lymph contains hepatic lymph and cholesterol synthesized in the intestinal walls. ${ }^{12)}$ However, in bile diverted-thoracic duct cannulated tats, lymphatic cholesterol levels were consistently low, indicating that they contribute very little to total cholesterol in thoracic lymph. For this reason, it is possible to determine the direct effects of $\mathrm{Cp}$ on cholesterol absorption in the intestinal tract by determining cholesterol levels in thoracic lymph. $\mathrm{Cp}_{\mathrm{p}}$ inhibited the absorption of exogenous cholesterol at two dose levels. Inhibition was greater at the higher dose. The same results were obtained when cholesterol absorption was promoted by the addition of cholic acid. Also, the increased levels of fecal cholesterol suggested that administration of chronic doses of $C p$ inhibited cholesterol absorption in rats. $\mathrm{Cp}_{\mathrm{p}}$ administration in a dose of $150 \mathrm{mg} / \mathrm{rat}$ also reduced the reabsorption of cholesterol beginning $2 \mathrm{~h}$ after administration. This inhibitory action of $\mathrm{Cp}$ on cholesterol absorption was consistent for more than $10 \mathrm{~h}$ but had completely disappeared within $24 \mathrm{~h}$. Since a preliminary experiment showed that most $\mathrm{Cp}$ had passed through the small intestinal tract about 10 $h$ after oral administration (unpublished observation), Cp may exert inhibitory action on cholesterol absorption only when it exists in the intestinal tract and its action is not the result of an irreversible dysfunction of the intestine.5)

Bile acids are essential for cholesterol absorption $^{11)}$ and $C_{p}$ binds with cholic acid in vitro (1.1 meq cholic acid/g Cp) ${ }^{2)}$ The hypocholesterolemic effects of cholestyramine ${ }^{9)}$ and neomycin ${ }^{13,14)}$ are thought to be the result of binding with bile acids and fatty acids in the intestinal tract, respectively. The binding of $\mathrm{Cp}_{\mathrm{p}}$ with cholic acid in the intestinal tract would be a cause of the inhibition of cholesterol absorption by $\mathrm{Cp}$. $\mathrm{Cp}$ reduced bile flow and biliary secretion of bile acids and cholesterol in fasted rats. Although lymph fistula did not affect bile secretion, bile fistula greatly reduced bile secretion in this study. Interruption of bile acids circulation caused a decrease in total bile acids pool under fasting conditions. The decrease in bile secretion due to $C_{p}$ may be attributable to the interruption of bile acids circulation, and not to the inhibition of cholesterol 
absorption. Fecal excretion of bile acids in the $\mathrm{Cp}$ treated group significantly increased; especially the bound bile acids fraction, most of which is thought to be bound to $\mathrm{Cp}$. These fidings suggest that bile acids bind to $\mathrm{Cp}$ in vivo so firmly that they are excreted in the form of a bile acids- $\mathrm{Cp}$ complex which has already been demonstrated in vitro. ${ }^{6)}$

After repeated administration of $\mathrm{Cp}$ to normally feeding rats, bile acids secretion again decreased and fecal excretion of cholesterol and bile acids increased. The reduction in bile acids secretion after repeated administration of $\mathrm{Cp}$ was less marked. However, bile acids content was dramatically reduced when bile was collected at later periods (Table II). Bile acids secretion following Cp treatment was thought to be different from that of the control. The serum cholesterol level was not altered by $C p$ treatment because the rate of hepatic cholesterol synthesis is rather high in rats $^{15)}$ and the turnover rate for cholesterol increases during $\mathrm{Cp}$ treatment. ${ }^{7)}$ These observations indicate that compensatory activity is initiated as a result of low cholesterol and bile acids levels after $\mathrm{Cp}$ treatment.

Cholesterol absorption was promoted by the addition of cholic acid in a previous study. ${ }^{16)}$ Cholesterol absorption was also dependent on the bile acids level in the intestinal tract under the present experimental conditions (Fig. 3); i.e., bile acids in the intestinal tract primarily promoted cholesterol absorption. It was also shown that $\mathrm{Cp}$ suppressed this promotive action of cholesterol absorption by bile acids. It seems reasonable to conclude from the data presented above that $\mathrm{Cp}$ in the intestinal tract inhibits cholesterol absorption by binding with bile acids. The inhibition of cholesterol absorption by cholestyramine was greater than that by $\mathrm{Cp}$. This may be attributable to the fact that cholestyramine binds more bile acids than $\mathrm{Cp}$ in vitro. ${ }^{2)}$

$\mathrm{C}_{\mathrm{p}}$ inhibited triglyceride absorption to the same extent as cholesterol (data not shown). It has been reported that triglyceride and fatty acids promote cholesterol absorption. ${ }^{17)}$ However, cholesterol absorption for $24 \mathrm{~h}$ did not decrease when triolein was omitted from the test emulsion in the present study and the cholesterol absorption rates at certain times did not closely reflect the rate of triglyceride absorption. It cannot be proposed that $\mathrm{Cp}$ reduces cholesterol absorption due to the inhibition of triglyceride absorption by another mechanism; e.g., inhibition of esterase. The inhibitory action of $\mathrm{Cp}$ was completely blocked by addition of cholic acid. Cp probably inhibits triglyceride absorption which is also partially mediated by bile acids ${ }^{11,17)}$ by the same mechanism; i.e., binding with bile acids.

\section{REFERENCES}

1) R.C.Thomas, R.Hsi, H.Harpootlian, T.D.Johnson and R.W.Judy: Preparation of $\left[{ }^{14} \mathrm{C}\right]$ colestipol hydrochloride and its disposition in the human, dog and rat, Atherosclerosis, 29, 9-23 (1978).

2) T.M.Parkinson, K.Gundersen and N.H.Nelson: Effects of Colestipol (U-26,597A), a new bile acid sequestrant, on serum lipids in experimental animals and man, Atherosclerosis, 11, $531-537$ (1970).

3) T.M.Parkinson, J.C.Schneider Jr. and W.A.Phillips: Effects of colestipol hydrochloride (U-26,597A) on serum and fecal lipids in dogs, Atherosclerosis, 17, $167-179$ (1973).

4) J.R.Ryan and A.Jain: The effect of colestipol or cholestyramine on serum cholesterol and triglycerides in a long-term controlled study, J. Clin. Pharmacol. , 12, 268-273 (1972).

5) H.D.Webster and J.A.Bollert: Toxicologic, reproductive and teratologic studies of colestipol hydrochloride, a new bile acid sequestrant, Toxicol. Appl. Pharmacol. 28, 57-65 (1974).

6) E.Marmo, A.P.Caputi, S.Cateldi and A.Amelio: 'Attivita' ipolipidemizzan'te ed ipocolesterolemizzante di un copolimero della tetraetilenepentamina e dell'epicloroidrina (U-26,597A), Giornale dell'Arteriosclerosi, 8, 229-242 (1970).

7) W.A.Phillips and G.L.Elfring: Effects of colestipol hydrochloride and neomycin sulfate on cholesterol turnover in the rat, Lipids, 12, 10-15 (1977).

8) J.L.Bollman, J.C.Cain, J.H.Grindlay, R.Minn and E.V.Hook: Techniques for the collection of lymph from the liver, small intestine, or thoracic duct of the rat, J. Lab. Clin. Med., 33, 1349-1352 (1948).

9) D.M.Tennent, H.Siegel, H.F.Zanelti, G.W.Kuron, W.H.Ott and F.J.Wolf: Plasma cholesterol lowering action of bile acid binding polymers in experimental animals, J. Lipid Res., 1, 469-473 (1960).

10) I.L.Chaikoff, B.Bloom, M.D.Siperstein, J.Y.Kiyosu, W.O.Reinhardt, W.G.Dauben and J.F.Eastman: $\mathrm{C}^{14}$ Cholesterol I. Lymphatic transport of absorbed 
cholesterol-4-C ${ }^{14}, \quad$ J. Biol. Chem., 194, 407-412 (1952).

11) M.D.Siperstein, I.L.Chaikoff and W.O.Reinhardt: $C^{14}$ Cholesterol V. Obligatory function of bile in intestinal absorption of cholesterol, J. Biol. Chem., 198, $111-114$ (1952).

12) J.D.Wilson and R.T.Reinke: Transfer of locally synthesized cholesterol from intestinal wall to intestinal lymph, J. Lipid Res., 9, 85-92 (1968).

13) W.W.Faloon, I.C.Pace, D.Woolfolk, H.Nankin, K.Wallace and E.N.Haro: Effect of neomycin and kanamycin upon intestinal absorption, Ann, N.Y. Aca. Sci., 132, 879-887 (1966).

14) C.R.Thompson, M.MacMahon and P.Claes: Precipita- tion by neomycin compounds of fatty acid and cholesterol from mixed micellar solution, Europ. J. Clin. Invest. , 1, 40-47 (1970).

15) W.A.Phillips, J.M.Ratchford and J.R.Schultz, "Atherosclerosis Drug Discovery," ed. by C.E.Day, Plenum Press, New York, 1976, p. 251.

16) G.V.Vahouny, H.M.Gregorian and C.R.Treadwell: Comparative effects of bile acids on intestinal absorption of cholesterol, Proc. Soc. Exp. Biol. Med., 101, 538-540 (1959).

17) G.V.Vahouny, C.H.Woo and C.R.Treadwell: Quantitative effects of bile salt and fatty acid on cholesterol absorption in rat, Am. J. Physiol., 193, 41-46 (1958). 